\title{
IN MEMORIAM: DE BELGISCHE LEGERDIENST \\ (1913-1994) : deel I
}

Inge Debruyne

\section{Inleiding}

Dit jaar is het 15 jaar geleden dat de legerdienst afgeschaft werd door toenmalig minister van Defensie, Leo Delcroix. We maken van deze gelegenheid gebruik om samen met een aantal gewezen dienstplichtigen terug te blikken op een ervaring die bij velen een diepe indruk nagelaten heeft en die ook zijn stempel drukte op onze samenleving.

We nemen meer bepaald de volgende thema's onder de loep: het schachtenleven, het dagelijkse leven in het leger, de eigenlijke opleiding, de voeding en keuken en de ontspanning en feesten. In een volgend deel zullen ook de anekdotes en verhalen, de taboes en straffen, het afscheid van het leger, de appreciatie van de legertijd en de aandenkens aan de legerdienst aan bod komen.

\section{Voorstelling van de geïnterviewde ex-miliciens}

1) Maurice B.

Lichting: $\quad 1940$

Kazernes: $\quad$ 13de Artillerie Brugge (71 dagen)

32ste Regiment Artillerie VDD/A/1 lLK (50 dagen)

Graad: $\quad$ soldaat-milicien

Functie: verzorger paarden

2) Jules $V$.

Lichting: $\quad 1956$

Kazernes: $\quad$ Sint Niklaas (3 maanden) - Koksijde (luchtmacht) (10 maanden)

Graad: $\quad$ soldaat-milicien

Functie: bediende (typist / administratie)

3) Frans D.

Lichting: 1968

Kazernes: $\quad$ Majoor Blairon Turnhout (3 maanden) - Hitfeld Aachen (Duitsland) (9 maanden) 
Graad: $\quad$ soldaat-milicien

Functie: $\quad$ chauffeur/magazijnier

4) Wilfried V.

Lichting: $\quad 1970$

Kazernes: $\quad$ Majoor Blairon Turnhout (3 weken) - Prins Boudewijn kazerne

Siegen (Duitsland) (11 maanden)

Graad: $\quad$ soldaat-milicien

Functie: $\quad$ chauffeur / bediende (administratie)

5) Daniël P.

Lichting: $\quad 1972$

Kazernes: Lombardsijde (5 maanden) - Essentho (Duitsland) (10 maanden)

Graad: $\quad$ Onderluitenant

6) Freddy L.

Lichting: $\quad 1973$

Kazernes: Majoor Blairon Turnhout (1 maand) - militair hospitaal Oostende (11 maanden)

Graad: korporaal

Functie: bediende (administratie)

7) Luc C.

Lichting: $\quad 1977$

Kazernes: $\quad$ Majoor Blairon Turnhout (1 maand) - Brugge (9 maanden)

Graad: $\quad$ soldaat-milicien

Functie: bediende (administratie)

8) Jimmy $\mathrm{H}$.

Lichting: $\quad 1984$

Kazernes: Koksijde (1 maand) - Grefarth-Hinsbeck (Duitsland) (7 maanden)

Graad: soldaat-milicien

Functie: luchtfuselier

9) Geert D.

Lichting: $\quad 1985$

Kazernes: $\quad$ Leopoldskazerne Gent (1 maand) - Lombardsijde (9 maanden)

Graad: soldaat-milicien

Functie: $\quad$ medewerker medische dienst 
10) Guy S.

$\begin{array}{ll}\text { Lichting: } & 1990 \\ \text { Kazernes: } & \text { Jambes (6,5 maanden) - Keulen (3,5 maanden) } \\ \text { Graad: } & \text { onderluitenant } \\ \text { Functie: } & \text { pelotonscommandant }\end{array}$

11) Jan D.

Lichting: $\quad 1992$

Kazernes: Majoor Blairon Tumhout (1 maand) - Zeebrugge (2 weken) Lissewege (8,5 maand)

Graad: $\quad$ soldaat-milicien

Functie: barman en klusjesman

\section{Het schachtenleven}

\subsection{De eerste dagen}

De eerste dagen in het leger waren voor de meeste dienstplichtigen onwennig. Alles en iedereen was nieuw en niemand was dan ook in feeststemming. Daarbij kwam nog dat de bleus vaak gekleineerd werden door anciens en door hun oversten.

De dagen verliepen voornamelijk met het toewijzen van kamers, het uitdelen van schoenen en kledij en met het opdelen van de miliciens in pelotons. Verder werden allerlei richtlijnen gegeven en kregen de miliciens inspuitingen.

De eerste twee weken moesten de miliciens doorgaans in de kazerne blijven. Met deze maatregel wou men voorkomen dat de miliciens zich te buiten zouden gaan aan alcohol, iets wat niet te rijmen viel met de inspuitingen.

\subsection{Doop}

Opvallend is dat slechts een minderheid van de geïnterviewde miliciens een doop meemaakte. In Turnhout zag Frans hoe bleus gedoopt werden door dronken anciens en hoe ze ingesmeerd werden met schoensmeer. Toen Wilfried in Turnhout verbleef bestond de 'wijding' van de bleus uit pintelieren in cafeetjes. Luc makkte zeven jaar later eenzelfde tafereel mee: schachten die liters bier achterover sloegen en zich vervolgens overgaven aan de feestvreugde.

In Koksijde beleefde Jimmy een andersoortige doop. Bij hem werd de voering uit zijn pet gesneden. Deze handeling stond symbool voor zijn ontmaagding in het leger. 


\section{Het dagelijks leven tijdens de opleiding}

\section{1 's Morgens}

De meeste geïnterviewden werden gewekt om 6u. Uitzonderingen waren Jan die om 5ul5 uit de veren moest, Geert die om 6ul 5 gewekt werd en Daniël en Guy voor wie de dag om 6 u30 begon.

$\mathrm{Na}$ het opstaan was er tijd voor een wasbeurt en voor het op orde brengen van de kamer.

Maurice moest na het opmaken van het bed meteen de paarden verzorgen. Dit nam 1 à 2 uur tijd in beslag nam. Pas daarna kon hij ontbijten.

Frans en Luc hadden 's morgens appel aan bed waarna Frans nog een cross van ongeveer $1 \mathrm{~km}$ moest lopen vooraleer hij zich kon wijden aan zijn ontbijt.

Om 8u - bij Freddy was dit $8 \mathrm{u} 30$ - stonden de miliciens klaar om te vertrekken naar de piste. Onderweg werd er gemarcheerd en op de piste zelf waren er oefeningen als kruipen, klimmen en lopen. Ook dril en schietoefeningen stonden op het programma. Sommigen hadden daarnaast theorielessen over wapens en oorlogsvoeren.

Maurice had geen boodschap aan 'ochtendgymnastiek'. Hij hoefde zich enkel bezig te houden met de paarden.

\section{2 's middags}

's Middags begaven de miliciens zich naar hun kamer om hun 'hamel' te halen (2 aluminium potjes waarbij één gebruikt werd voor aardappelen, vlees en gronten en het ander voor soep). Daarna gingen ze in rij staan en werd het eten op hun hamel geschept. Na het middagmaal wasten de miliciens hun hamel zelf af. Frans moest in een barak eten die bevoorraad werd door een veldkeuken. Het geleverde eten werd toen nog eens opgewarmd op een kachel. Ook Freddy at 's middags in een betonnen barak meermaals opgewarmd voedsel. Jan daarentegen at in een refter. $\mathrm{Na}$ of voor het eten had hij 'piket' waarbij hij elke week een andere taak kreeg: aardappelen schillen of tafels afruimen. Ook Jules oefende zich vlijtig in het aardappelen jassen tijdens zijn legerdienst.

\section{3 's namiddags}

De meeste miliciens moesten opnieuw aan de slag om $14 \mathrm{u}$. 's Namiddags waren er oefeningen op de piste, schietoefeningen of lessen. Meestal zat de 'training' erop om 17u. Jimmy was evenwel al vrij tussen 16 en $17 \mathrm{u}$ aangezien de beroepsmilitairen betrekkelijk vroeg huiswaarts keerden. 
Net zoals 's morgens was Maurice ook 's namiddag te vinden bij de paarden. Deze taak werd afgewisseld met lopen en met het leren omgaan met wapens. Tussen $15 \mathrm{u}$ en $16 \mathrm{u}$ moest hij naar binnen om lessen te volgen over oorlog en wapens. Zijn dagtaak was voorbij om $17 \mathrm{u}$.

\section{4 's avonds}

Rond $18 \mathrm{u}$, nadat de miliciens zich hadden opgefrist, gingen ze aan tafel. Daarna was bijna iedereen vrij. Er waren evenwel uitzonderingen: Geert was soms 'van piket' na het avondeten, Maurice had af en toe stalwacht van 's avonds tot 's morgens en Jan kreeg soms nog les 's avonds als de oversten niet tevreden waren: "Dat gebeurde nogal willekeurig. Het hing er vanaf hoeveel zin de oversten hadden. En als we 's namiddags wapenles hadden moesten we ons wapens 's avonds schoonmaken. Dat kon uitlopen tot 21 à 22 u."

Guy had zelfs elke maandag-, dinsdag- en woensdagavond verplichte studie tot $21 \mathrm{u}$. Op donderdagavond had hij vrij en mocht hij wegblijven tot $24 \mathrm{u}$.

De miliciens hadden over het algemeen heel wat mogelijkheden om hun vrije tijd in te vullen. Ze konden naar de kantine om iets te drinken, een gezelschapspel te spelen, te biljarten of een spelletje tafelvoetbal te spelen. Ook konden ze op de slaapzaal blijven om wat te babbelen of te kaarten. Op stap buiten de kazerne behoorde af en toe ook tot de mogelijkheden.

Daniël had zelfs permissie om naar huis te gaan slapen. Dit voordeel was ook de miliciens die getrouwd waren en dichtbij de kazerne van Koksijde woonden gegund, aldus Jimmy. Als Daniël in de kazerne bleef moest hij om $24 \mathrm{u}$ binnen zijn. Dit in tegenstelling tot de meeste geïnterviewden die om $22 \mathrm{u}$ terug in de kazerne dienden te zijn. De lichten gingen uit om middernacht. Bij Maurice, Jimmy en Geert gebeurde dit al om $22 \mathrm{u}$.

\section{De eigenlijke opleiding}

\subsection{Het marcheren en de oefeningen}

De eigenlijke militaire opleiding bestond voornamelijk uit kruipen, sluipen, over hindernissen springen, marcheren, lopen, klimmen en leren omgaan met wapens. Freddy: "De eerste week leerden we bevelen opvolgen en moesten we leren marcheren, kruipen en schieten. Gedurende de rest van de opleiding waren er lessen over wapens en over hoe we ons geweer moesten onderhouden, uit elkaar halen en terug in elkaar steken. We kregen daarnaast ook lessen EHBO." Wilfried herinnert zich nog een bijkomende oefening: "Wij hadden ook oefeningen aan een rek en daar hadden de meesten last mee. Ook met het mooi in de pas mar- 
cheren hadden velen moeite. Ik werd gelukkig vrijgesteld van bepaalde oefeningen omdat ik een 'cross-opleiding' volgde en omdat bepaalde oefeningen niet goed waren voor mijn spieren." Bij Freddy staat het marcheren in zijn geheugen gegrift: "Het marcheren gebeurde met een groep van een 25-tal miliciens waarvan de grootsten, die ook grote passen namen, vooraan en de kleinsten achteraan liepen. Iedereen moest in de pas blijven en goed doorstappen op het tempo "links rechts". Soms moesten we een rugzak dragen die toch een aantal kilo's woog. Daarmee moesten we marcheren en kruipen." Frans kan dit beamen: "We moesten met onze helm op, met pak en zak op de rug en met ons wapen al kruipend een soort hindernissenparcours afleggen. Daartoe hoorden paaltjes die zo'n $50 \mathrm{~cm}$ boven de grond waren gespannen. We moesten hieronder kruipen met pak en zak. Het was verboden om recht te staan. Ze zeiden: "We schieten met een mitrailleur die op een vast punt staat. Als je recht gaat staan ben je eraan." Er waren er die het geloofden en er waren er die het niet geloofden. Ik denk persoonlijk niet dat ze het gewaagd zouden hebben om met scherp te schieten. In elk geval had je er toch alle belang bij om niet recht te staan. Anders kreeg je sowieso een stamp in je achterste zodat je terug neerlag."

Luc bevestigt dat de opleiding niet geschikt was voor 'watjes': "Die opleiding was toch niet om te lachen, al hing het er wel van af wie je had. De ene was namelijk al wat harder dan de andere. In elk geval werd er veel geroepen en getierd en sommigen zagen serieus af. Zelf had ik er weinig last van want ik was nogal sportief."

Maurice werd van dit alles gespaard: "Ik moest mij voornamelijk bezighouden met de paarden. Af en toe moest ik 's namiddags wel eens een halfuurtje oefeningen doen. Dat was dan eens lopen of mijn geweer halen, openen, vullen en schieten."

\subsection{Theorielessen}

Ook theorielessen stonden op het programma: de miliciens leerden hoe je wapens uit elkaar haalde en terug in elkaar zette, wat de naam was van de verschillende wapenonderdelen en ze kregen praktische informatie over wapens en bommen en wat al dan niet gedaan hoorde te worden in bepaalde situaties.

Naast de lessen over wapens stond ook een EHBO-cursus op het programma. Voor Daniël en Guy die opgeleid werden tot KRO vormden de theorielessen de hoofdbrok van hun opleiding. Het fysieke aspect kreeg heel wat minder aandacht. Voor Daniël was dit zelfs beperkt tot een half uurtje sporten per week en tot sporadische oefeningen op de piste.

De opleiding van Frans kreeg na 6 weken een andere invulling. Hij werd opgeleid tot chauffeur: "In die weken werd mij heel wat bijgebracht over wagens, bijvoorbeeld over bandendruk, over de motor van een auto en over auto-onder- 
delen. Ik moest ook de Belgische en Duitse wegcode onder de knie krijgen en ik leerde rijden met zware vrachtwagens en met jeeps."

\subsection{Bivak}

Ook één of meerdere bivaks behoorden traditioneel tot de opleiding. Guy: "Dat was zwaar afzien! We vertrokken op bivak op maandag en keerden pas op vrijdag terug. Iedereen had een halve tent mee, dat wil zeggen een halve stok en een half zeil. We moesten dan per twee de tent opzetten. Iedereen had ook een rugzak bij met eten zoals beschuiten, confituur, koffie, corned beef en bonen. Ook een hamel, bestek en een komfoor behoorden tot onze uitrusting. We werden altijd ergens gedropt en kregen dan per twee een landkaart. 's Avonds moesten we op een bepaald punt samenkomen. Om de twee dagen kwam een vrachtwagen langs met warme maaltijden zodat we toch iets 'deftigs' binnenkregen. Elke avond waren we na het avondeten doodmoe en gingen we meteen slapen op ons matje dat soms gewoon in de sneeuw lag. Ik herinner mij dat iemand ooit eens is flauwgevallen van vermoeidheid. Hij werd weggevoerd en nadien hebben we die kerel nooit meer teruggezien."

Ook Jan herinnert zich nog levendig de driedaagse bivak die ze tijdens de derde week van hun opleiding hadden: "We vertrokken met ons geweer, met van alles en nog wat op onze rug en met onze helm op, ook al was het 30 graden. We moesten op anderhalf uur tijd $12 \mathrm{~km}$ afleggen naar de plaats waar we ons kamp zouden opslaan. Per twee zetten we er dan ons tentje op. Overdag maakten we tochten, deden we tactische oefeningen of beschermden we ons kamp. Af en toe waren er simulatieoefeningen. Zo kwam er eens een herder ons kamp binnen met 10 schapen, gespeeld door 11 miliciens. Ook kregen we twee zogenaamde dronkaards op bezoek. Het was een manier om te leren reageren op onverwachte situaties."

Ook nachtoefeningen maakten deel uit van de bivak. Jan: "In het begin werd er iemand aangesteld als spook die tijdens die drie dagen wakker moest blijven en om het uur naar het begin van het kamp moest lopen waar de officieren en onderofficieren sliepen. Het spook moest hen wekken zodat ze dril konden geven. Dit hield in dat iedereen moest opstaan en in een dijk moest gaan liggen met een geweer. Die zogenaamde alarmoefening duurde 10 à 15 minuten. Daarna mocht iedereen weer een uurtje gaan slapen. Er werd met andere woorden weinig geslapen in die drie dagen en dat gold zeker voor het spook. Die ongelukkige werd gekozen door ons, miliciens, via anonieme briefjes. De naam van de persoon die het meest voorkwam werd tot spook uitgeroepen.

Ook Frans kreeg een nachtoefening: "We werden in twee groepen ingedeeld en we moesten ons dan camoufleren, zo geruisloos mogelijk sluipen en onszelf ingraven. Het was de bedoeling dat de ene groep de andere verraste." Ook Jimmy 
ontkwam niet aan een nachtoefening: Wij moesten zo snel mogelijk vrachtwagens in- en weer uitladen en alles wegbergen. Daarna mochten we weer gaan slapen."

\section{Voeding}

Wat het eten betreft zijn de meningen verdeeld. Maurice, die zichzelf nochtans niet als kieskeurig bestempelt, vond de maaltijden ronduit slecht. Zijn lotgenoten waren dezelfde mening toegedaan. Veel van het afgedankt eten werd dan ook afgevoerd naar boerderijen in de buurt om te voeren aan de varkens. Elke week bracht Maurice eten mee van thuis en tijdens de week ging hij vaak frieten eten. Maurice: "Het ontbijt was wel oké: zoveel boterhammen als je maar wou, boter, kaas en koffie. Confituur bracht ik ook mee van thuis. Gezien alle plaatsen in de refter doorgaans bezet waren aten we vaak op bed."

Jules' ervaring was positiever: "Zowel in het opleidingscentrum in St. Niklaas als in de kazerne in Koksijde was het eten goed. In die tijd schakelden veel mensen over van boerenboter naar margarine omdat het veel goedkoper was. In Koksijde, waar voor het merendeel piloten zaten, bleef het bij boerenboter. 's Middags werd er een warme maaltijd voorzien en 's avonds brood. Het menu bestond uit 'gewone ménagekost'. Dat kon ook al eens vis, mosselen en paling zijn. Als er 'boulettes' op tafel kwamen zeiden ze daar: "er is weer een piloot verongelukt". Dat was zo een gezegde."

Frans herinnert zich de keuken als zijnde bijzonder slecht in Turnhout en iets beter in Aken. 'In Turnhout werd het eten 'à la vitesse' gemaakt. De namaakpuree die we kregen was een mooi voorbeeld daarvan. Het was nochtans niet altijd het eten zelf dat weinig appetijtelijk was. Als je keukenkarweitjes moest doen en zag hoe die grote kuipen maar afgewassen werden, had je eigenlijk al genoeg van het eten. Maar dat was niet het enige onsmakelijke: iedereen moest zijn eigen 'plateau' afwassen. Als je wat bij de laatsten of gewoon in het midden was om je hamel af te wassen, was het water in de kuip al degoutant vuil. De brokken vlees zwommen er gewoon in het rond." 's Morgens kregen Frans en zijn metgezellen brood met choco en als drank cacao voorgeschoteld. Ook 's avonds was er een broodmaaltijd. Slechts heel af en toe werd er een warme maaltijd bereid. In het Duitsland was het eten heel wat beter, al was het menu niet erg gevarieerd. Dit zorgde ervoor dat de miliciens zich vaak naar de kantine begaven om wafels, worstjes of leo's te kopen. Frans: "Ik had nog het geluk dat één van mijn kamergenoten kok was. Hij smokkelde soms bananen, pralines en andere lekkernijen mee naar onze kamer en deelde die dan met ons.

Ook Wilfried was betrekkelijk tevreden met het eten in Duitsland, al vond ook hij het gebrek aan afwisseling een minpunt. "In Siegen werd er 's middags een warme maaltijd voorzien en's avonds kregen we brood met beleg. Dat bestond 
meestal uit kaas. Wie honger had kon ook zoveel soldatenkoeken meenemen als hij maar wilde. Dat waren harde, droge koeken met weinig smaak maar ze stilden wel de honger. Op zondag was het altijd feest want dan kregen we krentenbrood en chocolademelk. In Turnhout hadden we minder geluk. Vooral het bivaketen stond ons tegen: elke dag bonen in tomatensaus."

Ook bij Freddy viel het eten in het opleidingscentrum niet bijster in de smaak: "We moesten in de barak uit aluminium potten eten. Het eten was niet vers want het was al eens opgewarmd en het was ook niet zo warm. In het militair hospitaal viel er niets op het eten aan te merken. Bij het ontbijt kregen we brood met kaas of charcuterie en soms een gekookt eitje. Om 10 uur kon je in de kantine een taartje kopen en koffie, cécémel of een pint drinken. 's Middags kregen we een warme maaltijd met dessert en 's avonds kregen we brood à volonté. De charcuterie werd wel geteld, je kreeg bijvoorbeeld 4 plakjes salami maar confituur kon je nemen zoveel als je wilde."

Net als Frans, Wilfried en Freddy liep Luc niet zo hoog op met het eten in Turnhout: "We hadden niet echt te klagen maar het waren ook niet bepaald feestmenu's. Toen we er de eerste keer aten zei de chef-kok: "Ik heb goed nieuws en slecht nieuws. Ik zal beginnen met het slechte: de soep is mislukt, maar het goede nieuws is dat er genoeg soep is voor iedereen!" Dat was een typisch voorval: er was altijd wel voldoende eten maar de kwaliteit liet vaak te wensen over." Luc had evenwel het geluk dat hij zowel in Tumhout als in Brugge af en toe moest meehelpen in de keuken. Zo kon hij dan zelf kiezen wat hij wou eten. In Brugge had hij ook het voordeel dat de maaltijden niet ter plaatse bereid werd en dat de miliciens uit borden konden eten in plaats van uit hamels.

Jimmy had het geluk dat het net 'maand van de soldaat' was toen hij in februari in Koksijde gestationeerd was. Bijgevolg kon hij een maand lekker eten. De keuken was er bovendien hygiënisch. Het contrast met Duitsland was dan ook groot: "Als je daar in de keuken kwam zag je gewoon de kakkerlakken wegspringen. Het gebeurde zelfs dat we kakkerlakken ij ons bord vonden! We hebben er dan ook niet zo veel gegeten. 's Middags en 's avonds gingen we vaak eten in een Italiaans restaurant in de buurt."

Geert's voorkeur op culinair vlak ging uit naar de Leopoldskazerne in Gent, ook wel 'hotel Leopold' genoemd: “We kregen hier heel behoorlijk te eten en soms hadden we zelfs keuze uit twee bereide schotels. Lombardsijde had eerder een typische grootkeuken maar ik ben er in elk geval niet vermagerd. 's Morgens en 's avonds was er een broodmaaltijd maar af en toe werd er iets warms klaargemaakt. 's Middags kregen we een volle maaltijd. Vooral in het weekend was het eten lekker, dan deden de koks extra hun best. 's Morgens kreeg je pistolets en chocomelk kon je ook altijd vragen."

Net als zijn voorganger liep Jan niet zo hoog op met het eten in Turnhout. Enkel de eerste dag konden ze duimen en vingers aflikken: "We kregen toen stoofvlees 
met frietjes maar dat was ook het enige culinaire hoogtepunt. Vooral als we op bivak trokken was het eten niet veel soeps. We moesten leven op beschuiten, soldatenkoeken, melkpoeder, corned beef en blik met zuurkool en worst of met tong in madeirasaus. Gelukkig kwam er na 24 uur een mobiele keuken. 's Morgens en 's avonds kregen we in de kazerne brood met choco, confituur en kaas en af en toe stond er wel eens macaroni of balletjes in tomatensaus op het menu 's avonds. In Lissewege was het eten wel voortreffelijk: "Elke dag kregen we er soep, hoofdgerecht en dessert. Als er officieren langskwamen was het helemaal feest: dan kwam er biefstuk, reerug of zelfs kreeft op tafel. Aangezien ik als barman ook meehielp met de bereiding van het eten kon ik ook wel wat meepikken. En als er een afscheidsfeest was kon iedereen aanschuiven aan de feestdis. We waren toen meestal met 140 à 150 man."

Daniël en Guy die het beiden tot onderluitenant schopten hadden nog het meest geluk. Zij kregen in Duitsland toegang tot de mess van de officieren en werden er aan tafel bediend. Ook konden ze kiezen uit verschillende menu's.

\section{Ontspanning}

\subsection{Vertier}

Binnen de kazerne bestond de ontspanning voornamelijk uit vertier in de kantine: iets drinken, kaarten, dammen, biljarten of een spelletje tafelvoetbal of tafeltennis. Ook TV-kijken of het bekijken van een film behoorde veelal tot de mogelijkheden. Velen lazen ook boeken of strips. Eén of meerdere keren per week hadden de miliciens permissie om zich buiten de kazerne te begeven.

$\mathrm{Na}$ de opleiding genoten de meesten meer vrijheid. Ze konden al eens vaker uitgaan maar niet iedereen maakte daar gretig gebruik van. Frans: "Wij gingen af en toe uit in Aken stad maar dat was niet zo bijzonder. Tot oktober 1968 moesten we de kazerne, tegen onze zin, verlaten in uniform want burgerkledij was verboden tot dan. De kazerne lag ook ver buiten de stad en we werden niet gerespecteerd door de Duitse burgers. Als Belgische soldaat moest je zeker geen Duits meisje ten dans vragen."

Wilfried en Geert maakten ook mee dat een vedette of charmezanger voor de nodige animatie kwam zorgen in de kazerne.

\subsection{Sport}

Sport stond niet echt bovenaan het lijstje van ontspanningsmogelijkheden, vaak omdat er een gebrek was aan - moderne - sportinfrastructuur. Luc had op dit vlak meer geluk: hij kon voetballen, zwemmen en lopen als hij dat wilde en op vrijdag had hij een vaste sportnamiddag. 
Geert voetbalde gewoonlijk op de koer van de Leopoldskazerne en Jan kon zich laten gaan in de sportzaal van de kazerne in Turnhout. In Zeebrugge kon hij eveneens voetballen en had hij net als Luc een sportnamiddag.

\subsection{Feesten}

Alle dienstplichtigen, behalve Maurice en Freddy, maakten wel eens één of ander feest mee. Dit kon variëren van een vliegmeeting (Jules), een bataljonfeest (Frans en Wilfried), een zelf georganiseerd feest binnen of buiten de kamer (Frans en Luc), machtsoverdracht bij de aanstelling van een nieuwe kolonel of korpscommandant (Wilfried en Jimmy), een galadiner (Daniël en Guy), een nieuwjaarsfeest (Luc in de hoedanigheid van barman), een receptie van een diensthoofd (Geert), een feest naar aanleiding van een pensioen, een speciale feestdag (bv. van de patroonheilige St Elooi) tot een feest ter gelegenheid van de verjaardag van de koning (Jan).

Op dergelijke dagen werd er volgens Jan 's voormiddags nog gewerkt. 's Middags kregen de miliciens een feestmaaltijd en daarna konden ze doorzakken tot 16 à $17 \mathrm{u}$.

\section{Conclusie}

$\mathrm{Na}$ een onwennige en vreugdeloze start raakten de miliciens, toen nog 'bleus', snel vertrouwd met het ritme van het leger: 's morgens opstaan, kamer opruimen, ontbijten en marcheren naar de piste waar allerhande fysieke of schietoefeningen gedaan werden. Deze oefeningen werden soms afgewisseld met lessen over wapens en oorlogvoering. 's Middags kregen de miliciens een volle maaltijd die over het algemeen als weinig smakelijk werd beschouwd. Na het afwassen en wegbergen van de eigen hamel waren er opnieuw oefeningen of lessen. Voor de jongemannen die een opleiding tot onderluitenant volgden bestond het programma hoofdzakelijk uit lessen. Het fysieke aspect kwam slechts in mindere mate aan bod. Na het avondeten, dat in de meeste kazernes bestond uit brood en beleg, konden de meesten, behalve degenen die van piket waren, studie of stalwacht hadden, zich ontspannen. Dit gebeurde in de kantine, op de kamer of soms buiten de kazerne. Af en toe werd het leven van de dienstplichtigen ook opgevrolijkt door één of ander feest.

\section{Noot}

1 Het Belgische leger was tot 1909 samengesteld uit lotelingen en vrijwilligers. In 1909 werd de dienstplicht voor één zoon per gezin van tel en in 1913werd de algemene dienstplicht ingevoerd. 